\title{
A relação entre mobilidade discente e evasão nos cursos de graduação
}

\author{
The relationship between student mobility and evasion in graduation \\ courses
}

\section{La relación entre la movilidad de los estudiantes y la evasión en los cursos universitarios}

Ana Paula Souza do Prado Anjos ${ }^{1}$; Marilde Queiroz Guedes²; Emília Karla de Araujo Amaral $^{3}$; Nilza da Silva Martins ${ }^{4}$

\begin{abstract}
RESUMO
Este estudo é um recorte de uma pesquisa do tipo estudo de caso, desenvolvida em uma universidade pública situada no estado da Bahia, Nordeste do Brasil. Teve por objetivo, analisar como a mobilidade discente tem influenciado os processos de evasão dos cursos de graduação dessa instituição. A compreensão das causas envolvidas no processo de mobilidade que levam os discentes a migrarem dos cursos e os impactos desse fenômeno para a instituição de ensino foram estudados a partir da análise do contexto local e das políticas de expansão do ensino superior no século XXI, à luz das concepções de diferentes teóricos e de censos divulgados pelo MEC. Os resultados da pesquisa apontam que o processo de mobilidade discente no ensino superior foi impulsionado pela expansão de oferta de vagas nas últimas duas décadas, que os cursos das áreas de engenharias e ciências médicas foram os mais procurados pelos estudantes que migraram da universidade analisada e que esta não dispõe de condições financeiras, estruturais e programas consolidados para conter a evasão e a desistência, especialmente nos cursos de licenciaturas, por serem processos complexos e motivados por diversos fatores.
\end{abstract}

Palavras-chave: Graduação; Mobilidade; Expansão; Evasão; Educação.

\begin{abstract}
This study is a cut-out of a case study type of research, developed at a public university located in the state of Bahia, Northeast Brazil. Its objective was to analyze how student mobility has influenced the processes of evasion from undergraduation courses of this institution. The understanding of the causes involved in the mobility process that lead students to migrate from the courses and the impacts of this phenomenon on the educational institution were studied from the analysis of the local context and policies for the expansion of university education in the 21st century, in light of the conceptions of different theorists and censuses disseminated by Brazil's Ministry of Education and Culture. The results of the research indicate that the process of student mobility in university education has been driven by the expansion of vacancies in the last two decades, that courses in the areas of engineering and medical sciences have been the most sought after by students who migrated from the university under analysis, and that the university does not have consolidated
\end{abstract}

\footnotetext{
1 Mestranda do Programa de Ciências Humanas e Sociais da Universidade Federal do Oeste da Bahia (UFOB) e Pedagoga da Universidade do Estado da Bahia (UNEB/Campus IX). E-mail: apanjos@uneb.br

2 Pós-Doutorado e Doutora em Educação. Professora Plena da Universidade do Estado da Bahia (UNEB-Campus IX) e Professora Permanente do Programa de Pós-Graduação em Ciências Sociais e Humanas da Universidade Federal do Oeste da Bahia (UFOB). E-mail: mguedes@uneb.br

${ }^{3}$ Mestre em Educação, Professora titular da Universidade do Estado da Bahia (UNEB/Campus IX) e da Faculdade São Francisco de Barreiras. E-mail: emilia@fasb.edu.br

${ }^{4}$ Doutora em Educação e Professora Adjunta da Universidade do Estado da Bahia (UNEB/Campus IX). E-mail: nlima@uneb.br
} 
financial, structural and program conditions to contain evasion and dropout, especially in undergraduate courses, because they are complex processes and motivated by several factors.

Keywords: Graduation; Mobility; Expansion; Evasion; Education.

\section{RESUMEN}

Este estudio es un recorte de un tipo de investigación de caso, desarrollado en una universidad pública ubicada en el estado de Bahía, en el noreste de Brasil. Su objetivo era analizar cómo la movilidad de los estudiantes ha influido en los procesos de evasión de los cursos de graduación de esta institución. La comprensión de las causas que intervienen en el proceso de movilidad que lleva a los estudiantes a migrar de los cursos y los impactos de este fenómeno en la institución educativa se estudiaron a partir del análisis del contexto local y de las políticas de expansión de la educación superior en el siglo XXI, a la luz de las concepciones de diferentes teóricos y censos difundidos por el Ministerio de Educación y Cultura de Brasil. Los resultados de la investigación indican que el proceso de movilidad estudiantil en la educación superior fue impulsado por la expansión de las vacantes en las dos últimas décadas, que los cursos en las áreas de ingeniería y ciencias médicas fueron los más buscados por los estudiantes que migraron de la universidad analizada, y que la universidad no tiene condiciones y programas financieros y estructurales consolidados para contener la evasión y la deserción, especialmente en los cursos de pregrado, porque son procesos complejos y motivados por varios factores.

Palabras clave: Universitario; Movilidad; Expansión; Evasión; Educación.

\section{INTRODUÇÃO}

A expansão do ensino superior no Brasil, nas últimas duas décadas, tem proporcionado a jovens e adultos oportunidades de mudarem a direção de seus processos formativos e buscarem cursos de graduação que proporcionem maior satisfação pessoal, reconhecimento social e retorno financeiro.

O ser humano, por natureza, vive em busca da satisfação de suas necessidades fisiológicas, emocionais ou espirituais. Está em constante processo de mobilidade, que é a capacidade de ir em busca de algo que melhor supre seus anseios. No processo de formação educacional, a busca por uma profissão que atenda às expectativas pessoais, sociais e econômicas é o que leva o estudante a tentar novas alternativas, experimentar novas áreas de conhecimento e mudar de direção em certos momentos, conduzindo-se a processos de mobilidade discente.

É dentro dessa nova dinâmica que se amplia o fenômeno da mobilidade ou migração discente, aqui entendido como processo pelo qual o estudante do ensino superior opta por outro curso de graduação que acredita ter maior afinidade, interesse profissional, econômico ou formativo, após o ingresso na universidade. Para ingressar no novo curso, o aluno abandona, transfere ou desiste da primeira graduação em que foi matriculado.

Esse tipo de mobilidade tem se intensificado, com projeção de crescimento, visto que, pesquisas como as de Li e Chagas (2017) e Nogueira et al. (2017) têm demonstrado que o aumento de oportunidades de migração intermunicipal e interestadual, assim como, a adoção do Sistema de Seleção Unificada - SISU, por diversas universidades, como modalidade de ingresso, tem propiciado de forma significativa a mobilidade discente na última década.

Para melhor compreendê-lo, discutiremos as concepções teóricas deste fenômeno, assim como, analisaremos como a expansão do ensino superior tem contribuído para o aumento dos índices de mobilidade discente e influenciado nos processos de evasão dos cursos de graduação de um dos departamentos da Universidade do Estado da Bahia (UNEB), localizada no interior do estado. 
Os achados são resultado de um estudo realizado pela Assessoria Pedagógica do Departamento lócus da investigação, sobre a situação acadêmica dos discentes dos cursos de graduação no período de 2012 a 2018. Foram obtidos a partir da análise de dados da instituição, registrados no Sistema de Registros Acadêmico - SAGRES, tendo como foco as seguintes dimensões: a) caracterização de ingresso, perfil e saída dos discentes e b) análise das consequências sociais, profissionais e acadêmicas na vida dos discentes evadidos.

\section{EXPANSÃO E DEMOCRATIZAÇÃO DO ACESSO AO ENSINO SUPERIOR NO BRASIL}

A democratização de acesso ao ensino superior pode ser considerada um imenso desafio para o Brasil, quando se verifica que apenas $21 \%$ dos jovens brasileiros, entre 25 e 34 anos têm graduação, conforme relatório da Organização para a Cooperação e Desenvolvimento Econômico (OCDE, 2019). Esse percentual é considerado muito baixo comparado a outros países latino-americanos como Argentina (40\%), Chile (34\%), Colômbia (29\%) e Costa Rica (28\%). O levantamento mostra também que no Brasil somente $33 \%$ dos graduandos conseguem terminar o curso no tempo esperado.

A taxa de analfabetismo entre a população com mais de 15 anos em 2019, foi 6,6\%, atingindo 11 milhões de pessoas, sendo que mais da metade ( $56,2 \%$ ou 6,2 milhões) vivem na região Nordeste, conforme dados do Instituto Brasileiro de Geografia e Estatística (IBGE, 2020), demonstrando dificuldades de acesso dos brasileiros à própria educação básica.

A pobreza, a desigualdade de acesso a todos os níveis de ensino, a concentração de renda, as fragilidades na formação docente e as condições de ensino são fatores que têm contribuído para as deficiências na educação brasileira. Infelizmente, o Estado e boa parte dos setores brasileiros não têm demonstrado tanta atenção no progresso de uma educação para o desenvolvimento sustentável e para a formação integral dos sujeitos. A preocupação maior tem sido a formação de mão-de-obra para promover o crescimento econômico e a disputa no mercado globalizado, conforme objetiva a Confederação Nacional da Industria - CNI (2014, p. 36) "para participar do clube dos países e empresas que controlam as fases mais nobres das cadeias globais de valor, o Brasil precisará ter uma população trabalhadora educada e preparada para navegar na economia do século XXI".

Entretanto, o discurso da elite empresarial brasileira é contraditório, pois, ao mesmo tempo que exige qualidade na educação, age como força política para a participação mínima do Estado e redução dos gastos sociais. A área de educação tem sido drasticamente afetada com o teto de gastos públicos regulamentado pela Emenda Constitucional (EC) 95/2016, e pela agenda neoliberal dos últimos governos.

Com a precarização da educação pública no Brasil, responsável pelo atendimento de cerca de $85,5 \%$ (IBGE, 2020) dos educandos da educação infantil ao ensino superior, a qualidade da formação para modernização da sociedade e para atender às demandas do mercado de trabalho e/ou a continuidade dos estudos no ensino superior, fica comprometida.

Para além disso, o sistema capitalista neoliberal tem promovido a desvalorização da formação humana, ao interferir nas políticas educacionais e curriculares, em prol de uma formação competitiva, individualizada e de rankeamento das instituições, baseada no paradigma da racionalidade técnica, na visão mercadológica do conhecimento, na formação de personalidades autoritárias, economicistas, competitiva do ponto de vista da eficácia e do lucro (TORRES SANTOMÉ, 2017). 
Ainda que o ensino brasileiro apresente deficiências estruturais, o acesso ao ensino superior é uma conquista que faz diferença na vida acadêmica, profissional, social e econômica dos estudantes, especialmente dos oriundos das classes marginalizadas, e que precisa ser assegurada como estratégia para o desenvolvimento econômico, político e social da sociedade brasileira (MAUÉS e SOUZA, 2013).

A educação enquanto direito social não está garantida em sua plenitude, visto que o acesso dos jovens e adultos ao ensino superior não fora efetivado de forma democrática, seja pela quantidade de vagas disponibilizadas em instituições públicas, pela defasagem no processo de educação básica ou falta de recursos para cursarem uma graduação em instituições privadas.

As desigualdades educacionais estão estritamente ligadas às condições socioeconômicas, conforme relatório divulgado em 2019, pelo Programa das Nações Unidas para o Desenvolvimento (PNUD, 2019), o Brasil foi classificado como o 70 país mais desigual do mundo, visto que os $10 \%$ mais ricos do Brasil concentram 41,9\% da renda total do país. Preocupante, os resultados da Pesquisa Nacional por Amostra de Domicílio (PNAD, 2019), apontam que tal situação é mais grave, haja vista que, em 2018, o rendimento da fatia mais rica da população subiu $8,4 \%$, enquanto os mais pobres sofreram uma redução de $3,2 \%$, e $1 \%$ dos brasileiros mais ricos ganharam 33,8 vezes mais que o total dos $50 \%$ mais pobres.

Cientes de que a educação é a base para mudança desse cenário de desigualdades, historicamente tem se registrado, no Brasil, diversas ações com a finalidade de expandir o quantitativo de vagas no ensino superior e, consequentemente, a democratização de acesso dos jovens à primeira graduação. A propósito, o Plano Nacional de Educação - PNE 2014-2024 prevê na Meta 12 elevar a taxa bruta de matrícula na educação superior para 50\% e a taxa líquida para 33\% da população de 18 a 24 anos com pelo menos $40 \%$ das vagas na rede pública (BRASIL, 2014).

Com a intenção de assegurar o controle social e a formação de mão de obra para o setor produtivo, sem utilizar-se de significativo aporte de recursos públicos, os governos militares promoveram o início da expansão privada do ensino superior neste país. De acordo com o Instituto Nacional de Estudos e Pesquisas Educacionais Anísio Teixeira - INEP (2010), a quantidade de matrículas nas universidades públicas ampliou-se de 59.624 em 1960 para 492.232 em 1980, enquanto que no setor privado, no mesmo período, houve um salto no quantitativo de 42.067 para 885.054 matriculados.

Número de Matrículas em Cursos de Graduação, por Categoria Administrativa - 1980-201 7

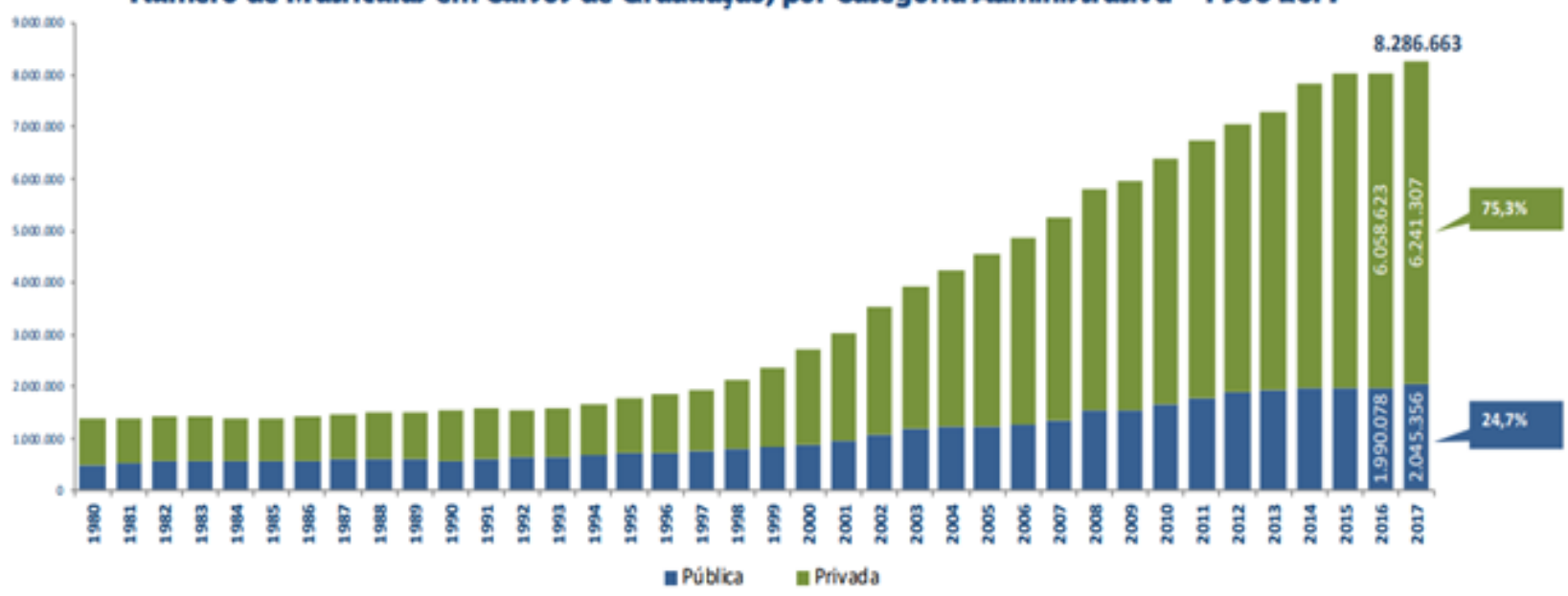

Fonte: Inep (2019).

Atualmente, a rede privada continua dominando o espaço na formação superior. De acordo com dados do INEP (2019), três em cada quatro alunos de graduação estudam em instituições 
particulares. Segundo Martins (2019), nas duas últimas décadas, o crescimento robusto das matrículas na rede privada se deu por ambientes e situações favoráveis e por grandes destinações dos orçamentos ao Programa Universidade para Todos (PROUNI) e, principalmente, para o Fundo de Financiamento Estudantil (FIES). Esse aporte orçamentário atraiu grandes grupos financeiros internacionais, com o objetivo de lucrar com a prestação de serviços educacionais.

Com pertinência, esses programas têm sido alvos de muitas críticas devido a destinação volumosa de recursos para instituições privadas, em vez de investir na educação superior pública, que propicia uma formação mais completa e tem apresentado melhor qualidade. Entre as universidades com nota máxima, $82 \%$ delas são públicas, e somente $18 \%$ são privadas, apontam dados do Exame Nacional de Desempenho de Estudantes (ENADE) de 2019. Embora as políticas públicas que facilitam o acesso ao ensino superior tenham a pretensão não só de inserir jovens e adultos na universidade, mas também propiciar melhores condições de participação no mundo do trabalho e na sociedade, é preciso nivelar as condições de oportunidades de participação e competição entre as diferentes classes.

Além desses programas, no decorrer do século XXI, começou-se a adotar outras medidas de ampliação de acesso ao ensino superior, entre elas: o Programa de Apoio a Planos de Reestruturação e Expansão das Universidades (REUNI); transformação dos Centros Federais de Educação Tecnológica em Institutos Federais de Educação de Ciência e Tecnologia (IFETs), implantação do Sistema Nacional de Formação de Profissionais do Magistério.

Destacamos que o FIES e o PROUNI foram utilizados para promover a sustentabilidade e ocupação das vagas ociosas nas instituições privadas, enquanto o REUNI se propôs a criar mais condições para a ampliação de acesso e permanência no ensino superior nas universidades públicas. Segundo Barros (2015) outras medidas como o "aumento da oferta de cursos superiores a distância e a política de cotas também contribuíram para reverter os índices baixíssimos de inclusão neste nível de ensino".

Em complemento ao plano de incentivo ao ingresso dos estudantes no ensino superior e como alternativa ao vestibular, em 2010, o governo federal criou o Sistema de Seleção Unificada - SISU. Esse sistema passou a ser utilizado por universidades federais, estaduais e municipais e pelos institutos federais de educação tecnológica. Em 2019 foram ofertadas 235.476 vagas em 129 instituições de ensino públicas em todo o país. Algumas instituições ainda adotam o SISU de forma parcial, mas boa parte das federais já aderiram ao sistema como única modalidade de seleção para ingresso.

Essas medidas contribuíram para a expansão e democratização do ensino superior no Brasil, de acordo com dados do Censo do Ensino, divulgados pelo INEP e demonstrados no Quadro 1.

Quadro 1 - Expansão do ensino superior no Brasil no Século XXI

\begin{tabular}{|c|c|c|c|c|c|}
\hline \multirow{2}{*}{ CATEGORIA } & \multirow{2}{*}{$\begin{array}{c}\text { TIPO DE } \\
\text { INSTITUIÇÃO }\end{array}$} & \multicolumn{4}{|c|}{ QUANTIDADE } \\
\cline { 3 - 6 } & $\mathbf{2 0 0 0}$ & $\mathbf{2 0 1 0}$ & $\mathbf{2 0 1 5}$ & $\mathbf{2 0 1 9}$ \\
\hline \multirow{2}{*}{$\begin{array}{c}\text { Instituições de } \\
\text { Ensino Superior }\end{array}$} & Pública & 176 & 278 & 295 & 302 \\
\cline { 2 - 6 } & Privada & 1.004 & 2.100 & 2.069 & 2.306 \\
\hline $\begin{array}{c}\text { Cursos de } \\
\text { graduação }\end{array}$ & Pública & 4.021 & 8.821 & 10.769 & 10.714 \\
\cline { 2 - 6 } & Privada & 6.560 & 19.756 & 22.732 & 29.713 \\
\hline $\begin{array}{c}\text { Vagas novas } \\
\text { ofertadas }\end{array}$ & Pública & 245.632 & 445.337 & 571.894 & 620.032 \\
\cline { 2 - 6 } & Privada & 512.161 & 2.674 .865 & 5.570 .255 & 11.146 .339 \\
\hline
\end{tabular}




\begin{tabular}{|c|c|c|c|c|c|}
\hline \multirow{2}{*}{ Ingressantes } & Pública & 198.942 & 435.710 & 534.361 & 559.293 \\
\cline { 2 - 6 } & Privada & 336.660 & 1.366 .191 & 2.385 .861 & 3.074 .027 \\
\hline \multirow{2}{*}{ Matrícula } & Pública & 887.026 & 1.461 .696 & 1.952 .145 & 2.080 .146 \\
\cline { 2 - 6 } & Privada & 1.807 .219 & 3.897 .424 & 6.075 .152 & 6.523 .678 \\
\hline
\end{tabular}

Fonte: Censo INEP 2000, 2010, 2015 e 2019.

Verifica-se que, no período de 2000 a 2010, a quantidade de instituições públicas aumentou em $68,1 \%$ e os cursos de graduação em 159,2\%, enquanto nas instituições privadas foram, respectivamente, $114,3 \%$ e $280,4 \%$. O aumento expressivo da quantidade de cursos e de ingressantes no período de 2000 a 2019 é resultado da política de acesso à graduação nas instituições privadas, por meio do PROUNI, implementado pelo governo federal em 2005. As instituições que aderiram ao programa receberam diversas isenções fiscais do governo, em troca da ocupação das vagas ociosas por estudantes de baixa renda e profissionais da educação. Esse programa tem sido alvo de diversas críticas, conforme aponta Silveira (2013), por mostrar-se como uma política focalizada, que coaduna com os interesses do capital e contribui para a privatização da educação superior.

Como resultado da expansão do ensino superior e mudanças de prioridade dos últimos governos, houve uma redução da quantidade de cursos em instituições públicas, sendo inauguradas apenas seis universidades nos últimos dois anos, de acordo com o Censo da Educação (INEP, 2017/2019).

O estímulo à expansão na iniciativa privada provocou, segundo Barros (2015, p. 368), o "rompimento com a ideia de universidade pautada na articulação entre ensino, pesquisa e extensão, o que permitiu a proliferação de cursos e instituições privadas com padrões mínimos de qualidade".

As tentativas de democratização do acesso ao ensino superior têm constituído em rentável empreendimento para o setor privado, principalmente, pelos subsídios governamentais, mas, em muitos casos, a qualidade do ensino promovido nestas instituições é preocupante.

Como a maior instituição multicampi do Estado da Bahia, a UNEB também acompanhou o processo de expansão do ensino superior, aumentando a quantidade de vagas nos cursos de graduação na capital e nos departamentos do interior, passando de 3.600 em 2002 para 4.074 em 2019. Para além das medidas adotadas pelo governo federal, com vista a democratizar o acesso à universidade, diversas instituições de ensino superior começaram a implantar política de cotas raciais e/ou sociais a partir do ano 2000, para garantir igualdade de oportunidades a determinados segmentos desfavorecidos na sociedade.

A UNEB foi pioneira na implantação da política de cotas raciais em 2002 , assegurando $40 \%$ das vagas nos cursos de graduação e pós-graduação para afrodescendentes. Em 2007 instituiu a reserva de 5\% das vagas ofertadas para indígenas. Devido a confirmação de demanda e a nova conjuntura social, em 2018, a instituição aprovou, por meio da Resolução no 1.339/2018, um novo sistema de reservas de vagas, a saber: para negros 40\%; indígenas 5\%; quilombolas $5 \%$; ciganos $5 \%$; deficientes, autistas e altas habilidades 5\%; transexuais, travestis ou transgênicos 5\%.

Na região Oeste da Bahia, a expansão do ensino superior se acentuou em 2006, com a implantação do Instituto de Ciências Ambientais e Desenvolvimento Sustentável (ICADS), vinculado a Universidade Federal da Bahia - UFBA, que passou a ofertar 6 (seis) cursos de graduação. Em 2009, o Campus já disponibilizava para a sociedade um total de 12 cursos presenciais. 
Em 2013, com o processo de reestruturação e expansão das federais, o ICADS foi transformado em Universidade Federal do Oeste da Bahia - UFOB, com sede na cidade de Barreiras-Ba, assumindo também a estrutura de multicampia. Com o status de universidade, a UFOB cresceu de forma expressiva, passando a ofertar em 20191.028 vagas em 30 cursos, pelo SISU, modalidade exclusiva de ingresso.

Barreiras conta ainda com a oferta de graduação pelo Instituto Federal da Bahia, que implantou os cursos de Matemática em 2008 (40 vagas), Engenharia de Alimentos em 2013 (40 vagas), e Arquitetura e Urbanismo em 2016 com 30 vagas anuais. Conta ainda com várias faculdades privadas de grande porte.

\section{A RELAÇÃO DA EXPANSÃO DE ACESSO AO ENSINO SUPERIOR COM A EVASÃO}

Atualmente, com a expansão do ensino superior, as universidades têm vivenciado uma nova dinâmica no tocante aos processos da não conclusão dos cursos de graduação pelos discentes. Para uma melhor compreensão, é preciso diferenciar a não permanência na universidade, que pode ser categorizada em três tipos principais de saída: evasão, exclusão e mobilidade discente.

A evasão é uma forma de saída de caráter ativo por parte do discente, que por motivos diversos opta por não dar continuidade aos estudos. Isso ocorre por abandono ou desistência formalizada do curso. Ocorre o abandono quando o discente não efetiva matrícula por dois semestres consecutivos nem solicita trancamento do curso. Já a desistência formalizada se dá quando o graduando solicita o seu desligamento do curso.

A desistência de um acadêmico representa uma perda social e de recursos de todas as partes envolvidas neste processo da educação. O mercado de trabalho perde uma pessoa capacitada e preparada, para as IES do setor público todos os recursos utilizados e investidos não têm retorno, nas IES privadas se perdem, além dos aspectos sociais, um prejuízo econômico e empresarial (CORDASSO, 2016, p.7).

A evasão e a desistência são permeadas por condições socioeconômicas, emocionais e culturais, que muitas vezes forçam a saída do ensino superior, daí a responsabilidade das instituições e do Estado. A falta de apoio pedagógico aos graduandos com necessidades especiais ou dificuldades de aprendizagem, de atendimento psicológico aos discentes com problemas de saúde mental e emocional, de bolsas de estudo aos que necessitam de recursos financeiros para custear as despesas com a aprendizagem, são algumas das situações que levam a saída dos estudantes. Essas condições retiram do estudante a capacidade de escolha em continuar ou não estudando. Já na mobilidade discente, o estudante faz a escolha por um outro curso.

Nesse sentido, Araújo (2013, apud VELOSO e ALMEIDA, 2001 p. 5) a define como "fenômeno de migração do aluno para outro curso, sem sair do sistema educacional, mas que não representa fracasso nem do aluno nem do professor, nem do curso ou da instituição, mas investimento e tentativa de buscar algo melhor e de maior identificação profissional".

Ao contrário da evasão que caracteriza como "fracasso escolar" (RANGEL et al., 2019, p. 28), a mobilidade promove a inclusão mais assertiva, oportuniza a continuidade à vida acadêmica, na medida resulta do amadurecimento da visão de mundo, das escolhas profissionais e do autoconhecimento. 
$\mathrm{Na}$ tentativa de esclarecer as diferenças conceituais entre evasão e mobilidade, Cardoso (2008), sinaliza que a mobilidade seria uma evasão aparente, em que o aluno muda de curso dentro da própria instituição ou para outra IES. "Já a evasão real se daria pelo abandono definitivo do sistema de ensino por parte do estudante, o que pode ser ocasionado por motivos: financeiros, acadêmicos ou sociais, possuindo uma áurea de exclusão e fracasso".

Entretanto, na visão de RANGEL et al. (2019, p.30) a expansão do processo de mobilidade acadêmica entre "as universidades da rede pública ou privada, quer seja na forma de transferência ou simplesmente abandono, e nova entrada na rede, facilitada pela existência do Exame Nacional do Ensino Médio (ENEM), do SISU e do Fundo de Financiamento Estudantil", é resultado da ampliação de vagas e criação de novos cursos e instituições nas últimas duas décadas.

Após a adesão das universidades ao processo seletivo SISU, o qual possibilita o estudante participar de várias seleções para ingresso no ensino superior, a desistência do ingressante ${ }^{5}$ tem sido o tipo de mobilidade mais significativa.

Como a Lei 12.089/2009 proíbe a ocupação de vagas simultaneamente em instituições públicas de ensino superior ou financiada com verba pública, a mobilidade discente não ocorre por abandono, pois, o ingresso em outro curso de instituição pública exige o desvinculamento formalizado da graduação em que foi matriculado anteriormente.

A mobilidade discente de que trata a referida lei não pode ser confundida com a mobilidade discente/acadêmica, que é realizada por meio de editais de seleção entre instituições conveniadas, como a que existe entre as quatro universidades estaduais da Bahia e duas federais, com o objetivo de promover o acesso do estudante à diversidade da cultura acadêmica das universidades conveniadas, favorecer a ampliação de sua vivência sociocultural e oportunizar o acesso a componentes curriculares necessários à integralização curricular.

A mobilidade discutida aqui é fruto de certo descontentamento com o curso escolhido, seja por fatores pessoais, acadêmicos, econômicos, sociais ou educacionais, que levam o discente a buscar outro curso com que tenha maior afinidade. Contrariando a afirmação de Araújo (2013) de que a mobilidade não representa fracasso do curso ou da instituição, percebe-se que qualquer processo de saída de uma instituição representa prejuízo econômico, desprestigio institucional e incapacidade de cativar os ingressantes e oferecer condições que despertem o interesse pelo curso inicialmente escolhido, especialmente, as licenciaturas.

As pesquisas realizadas a partir da década de 1990 sobre análises conceituais, causas, consequências e ações preventivas relacionadas à evasão, desistência e abandono na educação básica são bastante volumosas, mas no que se refere ao ensino superior só aumentaram, após a primeira década do século XXI. Contudo, ainda há muita divergência sobre os conceitos e os critérios para classificação de determinado tipo de saída, como uma das categorias mencionadas, pois cada instituição tem sistemas de acompanhamento próprios e entendimento diversificado. Daí a importância de maior aprofundamento dos estudos dessa temática, assim como, da concepção e efeitos da mobilidade discente, por ser um fenômeno que ganhou maior dimensão com o aumento de oportunidades de migração, devido a expansão do ensino superior.

${ }^{5} \mathrm{O}$ discente desiste do curso logo após fazer a matrícula e antes de iniciar as atividades acadêmicas para poder matricular em outro curso 


\section{IMPACTOS DA MOBILIDADE DISCENTE EM UM DOS DEPARTAMENTOS DA UNEB, 0 INTERIOR}

A acentuada expansão no ensino superior na região Oeste da Bahia tem modificado o cenário de um dos departamentos da UNEB, localizado nesta região, no tocante à permanência dos discentes nos cursos de graduação. Objetivando mapear a evasão nos cursos de graduação neste Departamento, a Assessoria Pedagógica do campus fez em 2018, uma pesquisa que demonstra os impactos da mobilidade discente, principalmente, nos cursos de licenciatura. Destacamos que a Universidade tem duas modalidades de ingresso: o SISU e o vestibular.

Foram analisados os registros acadêmicos de 2.172 graduandos que ingressaram no período de 2012 a 2018, identificando que os cursos de licenciaturas (Pedagogia, Matemática, Letras e Ciências Biológicas) apresentam maior índice de evasão (39,7\%). O maior quantitativo de abandono e desistência dos discentes ocorre no segundo semestre, tanto nos cursos de bacharelado como nas licenciaturas. A taxa de evasão entre os estudantes que ingressaram pelo SISU é de 52,6\%, bem mais significativa do que a taxa dos que foram admitidos pelo vestibular (29,2\%). Outro dado relevante é que $38,8 \%$ dos discentes demoram em média dez semestres para concluir o curso, quando o tempo mínimo são oito semestres.

Para compreender os motivos e as implicações da saída destes estudantes da universidade, realizouse outra etapa da pesquisa para analisar as consequências da evasão na vida acadêmica, social e profissional dos discentes que ingressaram entre 2012 e 2016, pelas modalidades vestibular e SISU, período de maior evasão. Dos 635 discentes evadidos neste período, 234 participaram da pesquisa respondendo um questionário com questões abertas. Os dados possibilitaram compreender que a saída dos discentes está significativamente relacionada à ampliação de oportunidades de ingresso em outros cursos e instituições.

Considerando que a não conclusão do curso de graduação é mais significativa nas licenciaturas, verifica-se que em outras universidades públicas do país, as licenciaturas não têm despertado interesse de ingresso, nem de permanência dos jovens. A falta de prestígio da profissão docente e a possibilidade de ascensão socioeconômica tem despertado pouco interesse dos jovens para ingressar ou permanecer nos cursos de licenciaturas (GATTI e BARRETO, 2009). A falta de interesse pelas licenciaturas ocorre tanto na escolha da primeira graduação, como nos casos de mudança de curso, conforme aponta o Gráfico 1.

Gráfico 1 - Modalidade de cursos escolhidos pelos discentes evadidos

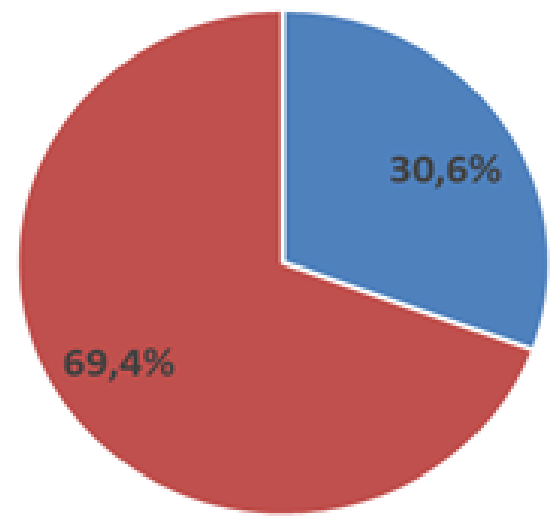

- LICENCIATURA

- BACHARELADO 
Dos 234 participantes da pesquisa, 173 ingressaram em outros cursos, destacando os de maior procura: bacharelados nas áreas de saúde, economia, agrárias e direito. 30,6\% escolheram licenciatura, grupo formado principalmente por discentes que anteriormente havia ingressado em cursos nesta modalidade e pretendem se dedicar à área de educação. É comum também que discentes escolham cursos de licenciaturas pela sua baixa concorrência, consequentemente, maior facilidade de ingresso. Porém, devido à falta de afinidade e de vislumbrar um futuro promissor, qualquer motivo pode levá-los a evadir.

Os motivos pelos quais os discentes evadem são diversos. Geralmente, a evasão está ligada a fatores que são comumente classificados em internos e externos. Os internos estão relacionados ao curso, infraestrutura, corpo docente e assistência sócio educacional. Já os externos relacionam-se ao aluno: falha na tomada de decisão em relação ao curso, dificuldades escolares, razões socioeconômicas, distância entre domicílio e a universidade, entre outros. (DIAS et al., 2010). No Campus de Barreiras, os fatores internos ou pessoais predominam, visto que a falta de interesse pelo curso escolhido é o principal motivo que levou os discentes a mudarem de graduação, como demonstra o Gráfico 2.

Gráfico 2 - Motivos da evasão no Campus

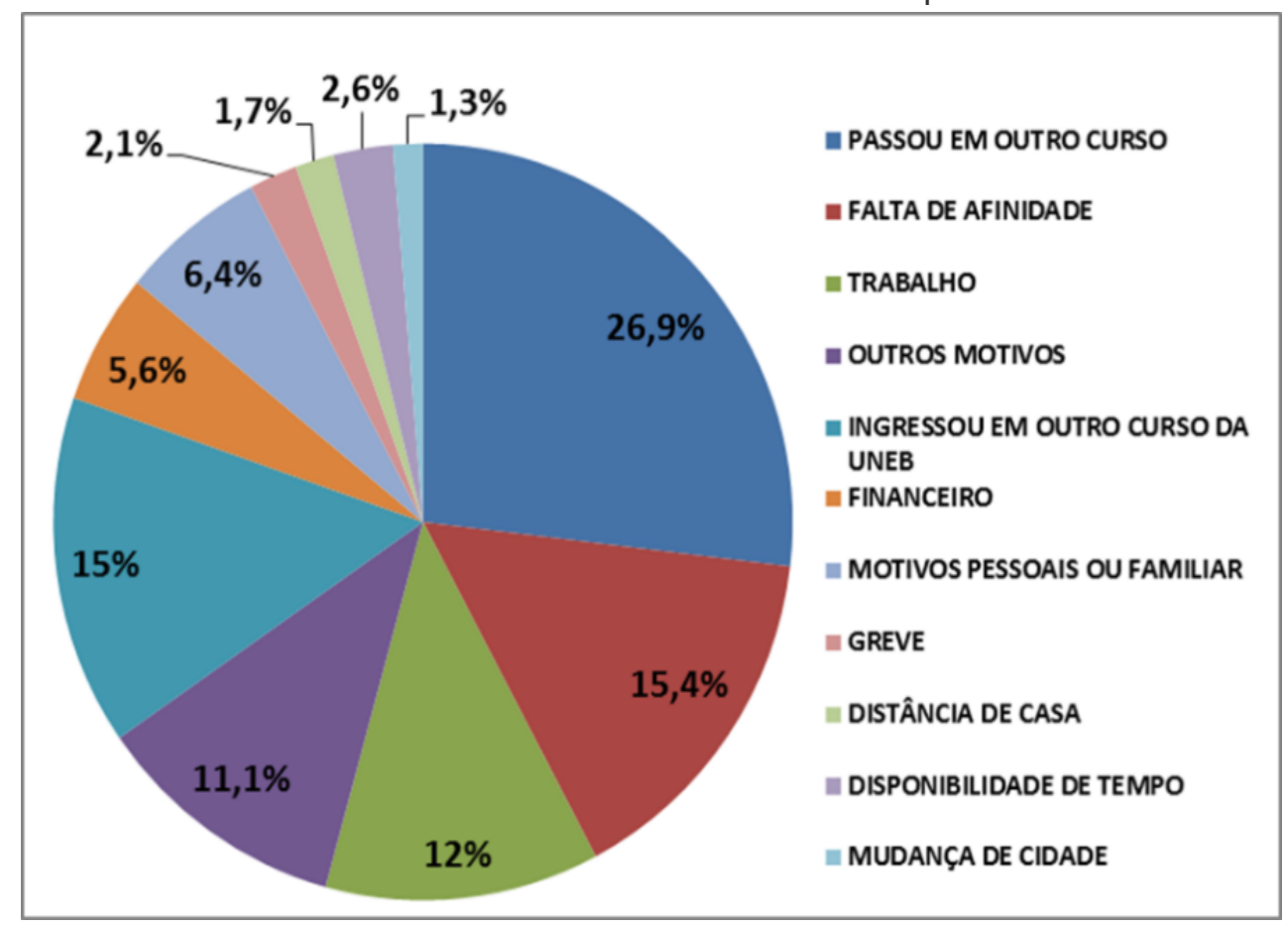

Fonte: ASPED

Ao relacionar o ingresso em outro curso (26,9\%), falta de afinidade $(15,4 \%)$ e ingresso em outro curso da instituição (15\%), subentende que 55\% dos ingressantes no Departamento não tinham a pretensão de permanecer no curso escolhido, fizeram a matrícula para não perder a oportunidade de ingressar na universidade, até ser aprovado no curso desejado. Essa tese é reforçada pelo fato de que a maioria desiste no primeiro ano de graduação e logo ingressam em outro curso, conforme demonstrado no Gráfico 3. 
Gráfico 3 - Evasão por semestre (\%)

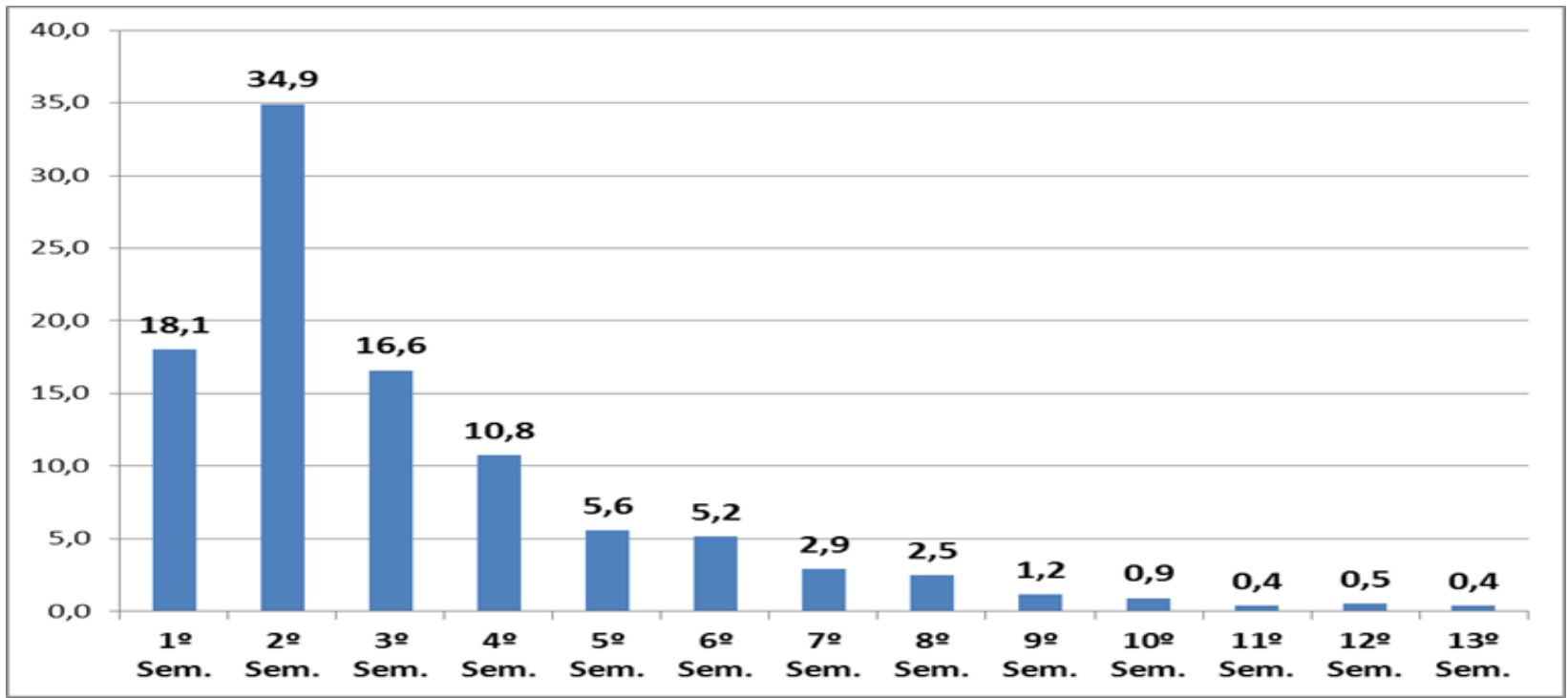

Fonte: ASPED

O primeiro ano é decisivo para os discentes resolverem pela continuidade ou não no curso, por isso, são necessárias mais ações focadas nos ingressantes, no sentido de motivá-los a permanecerem, apresentar as potencialidades profissionais da área de formação e integrá-los nas diversas atividades desenvolvidas pela instituição. Para os discentes que estão convictos em ingressarem em outro curso, essas ações podem não surtir efeitos, no entanto, essas medidas quando focadas nos indecisos podem contribuir para minimizar a evasão destes.

Os dados revelam que a expansão do ensino superior tem refletido na permanência ou não dos estudantes no primeiro curso de graduação. Atualmente, os graduandos não se veem presos a um curso por falta de oportunidade de migrar para outro que pode promover maior realização pessoal e/ou profissional.

Gráfico 4 - Realização de outra graduação pelos discentes evadidos

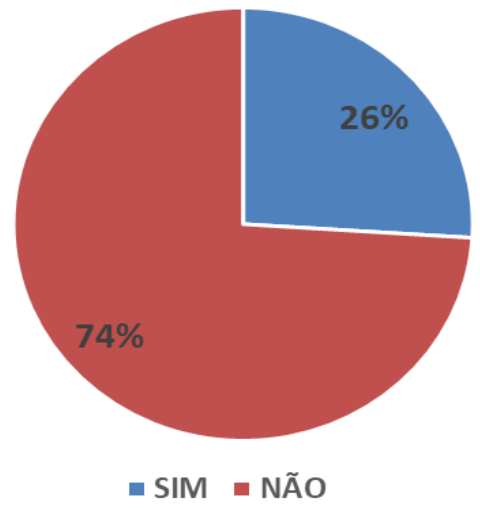

Fonte: ASPED

O gráfico mostra que $74 \%$ dos discentes evadidos, que ingressaram em outro curso, estão mais satisfeitos com a nova escolha, sendo que para $71 \%$, a saída da instituição não causou nenhum prejuízo social, acadêmico ou profissional para si, porque foi uma decisão pessoal. $\mathrm{O}$ destino da maioria dos evadidos deste Campus tem sido as universidades federais, destacando a UFOB, haja vista a oferta de melhores condições de permanência aos estudantes, ao disponibilizar programas de assistência estudantil e cursos mais valorizados socialmente e pelo mercado de trabalho. 
Gráfico 5 - Tipo de instituição que os evadidos ingressaram

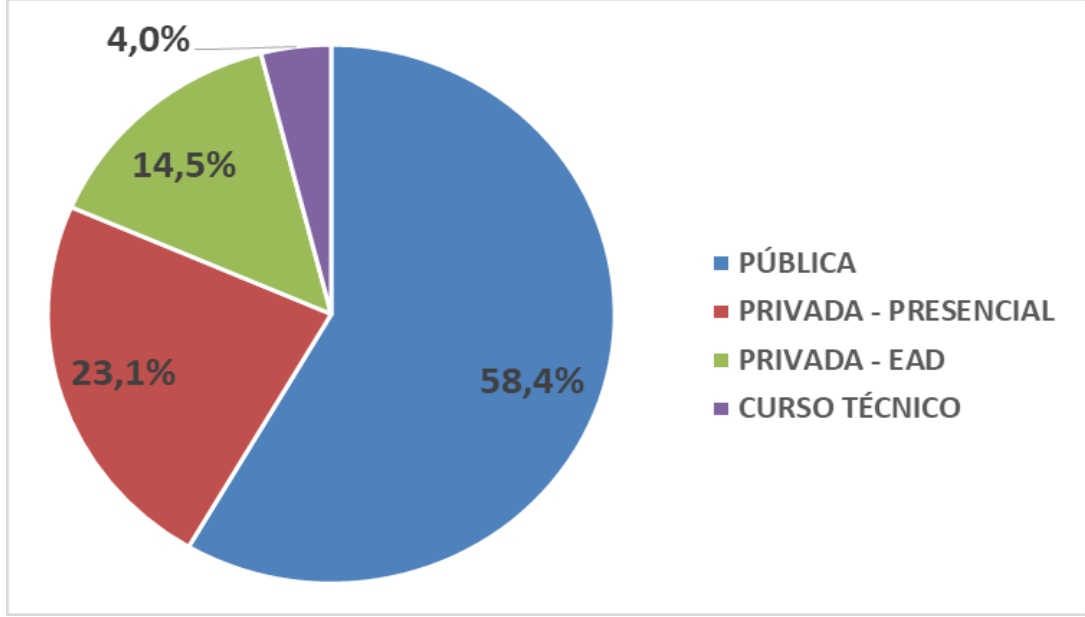

Fonte: ASPED

A qualidade do ensino tem sido levada em consideração na decisão de mudar de curso, tanto que os discentes preferem cursos presenciais em instituições públicas, visto que estas proporcionam maior reconhecimento e qualidade na formação dos acadêmicos, aspectos importantes no ingresso ao mercado de trabalho.

\section{CONSIDERAÇÕES FINAIS}

A formação em nível superior é considerada marco estratégico para o desenvolvimento social, cultural, econômico e de bem-estar da população. Nesse aspecto, o Brasil tem avançado pouco. As fragilidades na Educação Básica e a desigualdade social têm comprometido o acesso e permanência ao ensino superior, especialmente, em cursos mais concorridos e prestigiados social e economicamente. Mesmo com a disponibilização de diversos programas de acesso à formação universitária, as classes sociais marginalizadas conseguem acender pouco na vida acadêmica e econômica, por ter acesso a cursos com pouco reconhecimento, e profissões de baixa e/ou média remuneração. Nesta perspectiva, a qualidade da formação na Educação Básica, a situação financeira familiar e o acesso a outros níveis de conhecimento têm sido primordial para manutenção da divisão de classe no Brasil.

No século XXI, o Brasil tem vivenciado o maior acesso ao ensino superior e instituído diversos programas e ações para democratizar esta modalidade de ensino. No entanto, precisa avançar muito na ampliação de recursos, na criação de instituições, cursos e vagas em universidades públicas, visto que estas oferecem melhor qualidade de ensino e desenvolvem a formação que perpassa pelo ensino, pesquisa e extensão, proporcionando aos graduandos formação integral e integrada às demandas da sociedade. No processo de expansão do ensino superior, tem-se verificado uma nova dinâmica na permanência dos estudantes nos cursos e instituições. Os índices de evasão também aumentaram, mas quando se analisa as formas de evasão se percebe que está havendo um acentuado processo de mobilidade ou migração discente.

Por terem maior poder de escolha, os discentes estão desistindo do primeiro curso para ingressarem em outro que tenha mais afinidade, status e retorno financeiro. Diante disso, os cursos de licenciatura têm sofrido certo esvaziamento, tanto na procura quanto na permanência dos estudantes. 0 quantitativo de estudantes que sai da graduação sem concluí-la e ingressa em outro curso é significativo. Isso demonstra que a migração dos estudantes entre os cursos tem sido benéfica para 
os mesmos, mas causa enormes prejuízos financeiros, acadêmicos e de prestígio social para as universidades.

As instituições de ensino superior precisam analisar criteriosamente os motivos das saídas dos estudantes e focar em ações que possibilitem a permanência dos mesmos, sob o risco de fechar cursos de graduação por pouca demanda e quantitativo de matriculados.

Neste sentido, é importante que as coordenações dos colegiados dos cursos de graduação construam estratégias para a permanência dos estudantes. A reorganização dos componentes curriculares que são ofertados, bem como a escolha dos docentes que estarão com os graduandos/as nos primeiros semestres é determinante para a construção do encantamento dos estudantes com o curso.

A elaboração de políticas de permanência dos estudantes precisa estar inserida nos programas estratégicos dos departamentos, pois são imprescindíveis para o fortalecimento dos cursos de graduação. Essas políticas devem ultrapassar os aspectos financeiros que se concretizem em bolsas, residências universitárias, restaurantes, mas também aos apoios psicopedagógicos, que são indispensáveis neste momento de construção da vida profissional.

\section{REFERÊNCIAS}

ARAÚJO, Cristiane F. de; SANTOS, Roseli A. dos. A educação profissional de nível médio e os fatores internos/ externos às instituições que causam a evasão escolar. In: Anais ...

INTERNATIONAL CONGRESSO UNIVERSITY - INDUSTRY COOPERATION. São Paulo: Taubaté, 2012. [online] Disponível em: http://www.unitau.br/unindu/artigos/pdf525.pdf? Acesso em: 10 de set. 2019.

BARROS, Aparecida da Silva Xavier. Expansão da educação superior no Brasil: limites e possibilidades. Educação e Sociedade, Campinas - SP, v. 36, n. 131, p. 361-390, abr./jun. 2015. [online] Disponível em: https://www.scielo.br/pdf/es/v36n131/1678-4626-es-36-131-00361.pdf. Acesso em: 06 ago. 2020.

BRASIL, Presidência da República. Lei no 13005, de 25 de junho de 2014. Aprova o Plano Nacional de Educação - PNE e dá outras providências. DOU, Brasília, 25 de junho, 2014. [online] Disponível em: http://www.planalto.gov.br/ccivil_03/_ato2011-2014/2014/lei/l13005.htm. Acesso em: 18 ago. 2020.

BRASIL. Lei no 12.089 de 11 de novembro de 2009. [online] Disponível em: http://www.planalto.gov.br/ccivil_03/_Ato2007-2010/2009/Lei/L12089.htm. Acesso em: 28 de ago. 2019.

CARDOSO, Claudete Batista. Efeitos da política de cotas na Universidade de Brasília: uma análise do rendimento e da evasão. Brasília-DF, UNB, 2008. Dissertação, Universidade de Brasília, 2008. [online] Disponível em:

https://repositorio.unb.br/bitstream/10482/1891/1/2008_ClaudeteBatistaCardoso.pdf. Acesso em: 13 maio 2020.

CARVALHO, Márcia Marques de; WALTENBERG, Fábio D. Desigualdade de oportunidades no acesso ao ensino superior no Brasil: uma comparação entre 2003 e 2013. Economia Aplicada, Ribeirão Preto-SP, v. 19, n. 2, p. 369-396, abr./jun. 2015. [online] Disponível em:

https://www.scielo.br/pdf/ecoa/v19n2/1980-5330-ecoa-19-02-00369.pdf. Acesso em: 06 ago. 2020. 
CNI - CONFEDERAÇÃO NACIONAL DA INDÚSTRIA. Educação para o mundo do trabalho: a rota para a produtividade. Brasília: CNI, 2014. 49 p. [online] Disponível em:

http://arquivos.portaldaindustria.com.br/app/conteudo_18/2013/07/24/4499/201310280950181216 91a.pdf. Acesso em: 13 maio 2020.

CORDASSO, Jéssica Akemy et al. Fatores determinantes na evasão de acadêmicos no ensino superior: estudo em um município do norte mato-grossense. In: Anais... XVI Coloquio Internacional de Gestión Universtiraria - CIGU. Arequipa: Perú, 2016. [online] Disponível em: https://repositorio.ufsc.br/bitstream/handle/123456789/171967/OK\%20\%20101_00407\%200K.pdf?sequence=1\&isAllowed=y. Acesso em: 10 ago. 2020.

DIAS, Ellen Christine Moraes et al. Evasão no ensino superior: estudo dos fatores causadores da evasão no curso de Ciências Contábeis da Universidade Estadual de Montes Claros - Unimontes MG. In: Anais ... CONGRESSO USP DE INICIAÇÃO CIENTÍFICA EM CONTABILIDADE. São Paulo, 2010. [online] Disponível em https://congressousp.fipecafi.org/anais/artigos102010/419.pdf. Acesso em 10 de dezembro de 2019.

FIALHO, Nadia Hage. Universidade multicampi. Brasília: Autores Associados, 2005. 128 p.

GATTI, Bernadete Angelina; BARRETO, Elba Siqueira de Sá. (org.). Professores do Brasil: impasses e desafios. Brasília: UNESCO, 2009. 294 p.

IBGE - Instituto Brasileiro de Geografia e Estatística. Pesquisa Nacional por Amostra de Domicílios Contínua (2019). [online] Disponível em https://agenciadenoticias.ibge.gov.br/agencia-sala-de-imprensa/2013-agencia-denoticias/releases/28285-pnad-educacao-2019-mais-da-metade-das-pessoas-de-25-anos-ou-maisnao-completaram-o-ensino-medio. Acesso em 20 de dezembro de 2020.

INEP. Instituto Nacional de Educação e Pesquisa. Índice Geral de Cursos (IGC). Brasília: INEP, 2016. [online] Disponível em: http://portal.inep.gov.br/indice-geral-de-cursos-igc. Acesso em: 10 dez. 2019.

INEP. Instituto Nacional de Estudos e Pesquisas Educacionais Anísio Teixeira. (2000, 2010, 2015 e 2019). Sinopse Estatística da Educação Superior Graduação. Brasília, DF. [online] Disponível em: www.inep.gov.br. Acesso em: 30 de nov. 2020.

LI, Denise Leyi; CHAGAS, André Luís Squarize. Efeitos do SISU sobre a migração e a evasão estudantil. In: Anais... Encontro Nacional da Associação Brasileira de Estudos Regionais e Urbanos - ENABER. São Paulo, 2017. [online] Disponível em: http://www.acquaviva.com.br/ENABER17/ProgramacaoDefinitivaENABER_site.pdf. Acesso em: 08 ago. 2020.

MARTINS, Thiago de Melo. Evolução da mercadorização do ensino superior privado no

Brasil: caminho sem volta? Ensaios Pedagógicos, Sorocaba-SP, v. 3, n. 2, p. 37-44, mai./ago. 2019. [online] Disponível em:

http://www.ensaiospedagogicos.ufscar.br/index.php/ENP/article/view/131/164. Acesso em: 18. Nov. 2020.

MAUÉS, Olgaíses Cabral; SOUZA, Michele Borges de. A expansão da educação superior no Brasil e as políticas de formação de professores. Cadernos de Educação, Pelotas-RS, n. 45, p. 68-81, maio/ago. 2013. [online] Disponível em:

https://periodicos.ufpel.edu.br/ojs2/index.php/caduc/article/view/3823/3075. Acesso em: 22 ago. 
2020.

NOGUEIRA, Cláudio Marques Martins et al. Promessas e limites: o SISU e sua implementação na Universidade Federal de Minas Gerais. Educação em Revista, Belo Horizonte - MG, v. 33, p. 131, 2017. [online] Disponível em:

https://www.repositorio.ufop.br/bitstream/123456789/8674/1/ARTIGO_PromessasLimitesSisu.pdf. Acesso em: 10 ago. 2020.

OCDE - Organização para a Cooperação e Desenvolvimento Econômico. (2015). Education at a Glance 2019. OECD Indicators, OECD Publishing, Paris. [online] Disponível em:

https://www.oecd.org/brazil/Education-at-a-glance-2015-Brazil-in-Portuguese.pdf. Acesso em: 12 de ago. 2020.

PNUD - Programa das Nações Unidas para o Desenvolvimento. Relatório do Desenvolvimento Humano 2019. New York-USA: PNUD, 2019. [online] Disponível em:

http://hdr.undp.org/sites/default/files/hdr_2019_pt.pdf. Acesso em: 22 ago. 2020.

RANGEL, Flaminio de Oliveira et al. Evasão ou mobilidade: conceito e realidade em uma licenciatura. Ciência \& Educação, Bauru-SP, v. 25, n. 1, p. 25-42, 2019. [online] Disponível em: https://www.scielo.br/pdf/ciedu/v25n1/1516-7313-ciedu-25-01-0025.pdf. Acesso em: 18 ago. 2020.

SILVEIRA, Grazielle Vital da. A adesão das instituições privadas ao PROUNI: interesses em pauta. Mato Grosso, UFMG, 2013. Dissertação, Universidade Federal de Minas Gerais, 2013. [online] Disponível em: http://bdtd.ibict.br/vufind/Record/UFMT_b0a5f2420c1c53a950455204c78c8c83. Acesso em: 22 jun. 2020.

TORRES SANTOMÉ, Jurjo. Políticas educativas e curriculares na construção de um senso comum neoliberal. In: FLORES, Maria Assunção; MOREIRA, Maria Alfredo; OLIVEIRA, Lia Raquel. Desafios curriculares e pedagógicos na formação de professores. 2. ed. Santo Tirso/PT: De Facto, 2017. p. $51-72$

Submissão: 23/12/2020

Aceito: 26/01/2021 